\title{
GCU
}

Glasgow Caledonian

University

University for the Common Good

\section{The durability of building materials under a changing climate}

Phillipson, Mark C.; Emmanuel, Rohinton; Baker, Paul H.

Published in:

Wiley Interdisciplinary Reviews: Climate Change

DOI:

10.1002/wcc.398

Publication date:

2016

Document Version

Author accepted manuscript

Link to publication in ResearchOnline

Citation for published version (Harvard):

Phillipson, MC, Emmanuel, R \& Baker, PH 2016, 'The durability of building materials under a changing climate', Wiley Interdisciplinary Reviews: Climate Change, vol. 7, no. 4, pp. 590-599. https://doi.org/10.1002/wcc.398

\section{General rights}

Copyright and moral rights for the publications made accessible in the public portal are retained by the authors and/or other copyright owners and it is a condition of accessing publications that users recognise and abide by the legal requirements associated with these rights.

Take down policy

If you believe that this document breaches copyright please view our takedown policy at https://edshare.gcu.ac.uk/id/eprint/5179 for details of how to contact us. 


\section{WIREs Climate Change}

\section{Article type: Focus Article}

\section{Article title: The durability of building materials under a changing climate}

\section{Authors:}

Full name and affiliation; email address if corresponding author; any conflicts of interest

First author

Mark C. Phillipson*, Glasgow Caledonian University, Glasgow, UK.

Mark.phillipson@gcu.ac.uk

Second author

Rohinton Emmanuel, Glasgow Caledonian University, Glasgow, UK.

Third author

Paul H Baker, Glasgow Caledonian University, Glasgow, UK.

"This is the peer reviewed version of the following article: "The durability of building materials under a changing climate", which has been published in final form at WIREs Clim Change 2016. doi:

10.1002/wcc.398. This article may be used for non-commercial purposes in accordance with Wiley Terms and Conditions for Self-Archiving."

Abstract

Weathering of materials leads to degradation of the fabric of buildings which if left unchecked will lead to an increase in the rate, and possibly severity, of degradation. Adjustments to maintenance regimes could accommodate marginal changes to degradation rate. However, for significant increases in degradation rate, adaptations may be required. Globally, any new deterioration mechanisms are unlikely. However, in the future previously insignificant problems may start to become significant at a local level, for which there is a lack of local knowledge or experience.

Adaptation in the context of existing buildings is a means to further protect the existing fabric, to consolidate performance and control the rate of deterioration. This adaptation goes beyond the scope of enhanced maintenance. For historic buildings there will be tension between the need to 
conserve the building and simultaneously adapt in the face of increased climate change driven weathering. Impact studies are needed to identify priorities for adaptation by identifying the scale and impact of degradation related defects for the future building stock. Such studies need to be integrated with authoritative information on projected future climate.

Adaptation of building design is needed to ensure new buildings consider performance in both current and future climates. A whole-life approach to building design is needed. To achieve this building standards and building codes need to be developed which consider future climate design. Traditional vernacular styles may offer an opportunity for learning design lessons and adapting design practices that could help facilitate appropriate climate protection.

Introduction

The built environment has always been an important sector of human activity, and climate change has been identified as a particular pressure for change. Much attention has been given to the potential for achieving mitigation through the reduction of anthropogenic greenhouse gas emissions and has led to bodies such as the European Union agreeing directives requiring its member states to seek improvement ${ }^{1}$. However, it is also recognized that the built environment will be exposed to some of the potential impacts of climate change ${ }^{2}$ and therefore there is a need to proactively plan adaptation. The service life of buildings around the world varies considerably, but the expectation for many countries is that buildings should last a number of decades and a default value of 50 years is often used for assessments internationally ${ }^{3}$. In the case of UK housing a service life of at least 50 years is typically assumed, although we have many older buildings than this and it has been argued that much of the housing stock will need to last a century or more ${ }^{4}$. The comparability of timescales for climate change and the projected life of buildings means that in future there will be a risk of significant climatic performance problems for buildings that are currently problem free ${ }^{5}$. As the climate changes, we may need to start considering how this may impact on the service life of structures ${ }^{6}$. The risk for existing buildings is that the evolving climate exposes the building to conditions for which it wasn't designed to cope and, where this becomes significant, the concept of residual service life will become more important ${ }^{7}$. For new buildings the challenge should be to design a structure that will be able to tolerate these changing climatic conditions.

Buildings are usually designed to provide protection to occupants from the climate, and furthermore to achieve a specified internal environment regardless of the external climate. To achieve this, the design process needs to consider the climate, select appropriate materials, and provide detailing which will enable the building to function. Essentially there are three important aspects to designing for good performance:

1. Protecting the building and its contents against climate loads;

2. Maintaining good performance in the face of weathering and other degradation mechanisms; 
3. Allowing ventilation to control internal temperatures, moisture levels and maintain internal air quality.

Typically, the design process has used historic climate data to determine the likely excesses that the building may face and thus determine the risk level from climate loadings that the building may need to deal with. This approach is no longer adequate - those involved in the development work for building codes and standards are now being encouraged to consider future climate performance requirements ${ }^{8}$. However, a significant proportion of the current building stock has been built based on historic climatic design requirements.

Certain sections of the built environment, for example historic buildings, may be particularly vulnerable to climate change and potential remedial responses could be problematic. In the case of historic buildings, studies have been undertaken to investigate the nature of some problems and solutions ${ }^{9}$.

Other studies have looked into some of the potential catastrophic changes that may impact on the built environment, such as changes in the risk of flooding ${ }^{10,11}$. This paper focuses on the issue of building materials and how they perform in the context of weathering in a changing climate within the built environment. Inundation by flood water may prove to be a significant challenge for materials durability, but the consequences of these catastrophic events are not discussed further here, as many standardized approaches to remediation have been published. This paper does not consider a purely isolated view of the materials science, but instead seeks to place it within the context of the building design and detail. For example, the suitability of different construction types for different climatic regions is not just governed by the main materials, but also by the way the components are brought together. A building is usually a composite structure and the interfaces between different components are important, and can often be a source of weakness which can lead to defective building performance.

\section{Properties of materials in relation to weather and climate}

The external elements of a building, known collectively as the external building fabric or envelope, are designed to protect the internal environment from unwanted interaction with the external climate. There is considerable variation globally in what these types of loading may be, but generically this includes:

- Protection from external temperature conditions (both heat and cold);

- Protection from precipitation;

- Protection from winds (maintaining both structural integrity and shelter whilst enabling appropriate ventilation);

- Protection from external humidity conditions (through appropriate ventilation to control psychrometry).

Until relatively recently the majority of construction has relied upon locally sourced materials, and so regional construction styles largely reflected the availability of suitable materials and developed a 
traditional design style ${ }^{12}$ which achieved a suitable level of climate performance, with a realistic level of maintenance needed to keep the building functional. These vernacular constructions were, by a process of natural evolution ${ }^{13}$, successful constructions which were naturally climate resilient structures within the context of their local historical climates and were therefore replicated regionally ${ }^{14}$. Traditional structures in tropical climates tend to have lightweight wall constructions with large window openings for natural ventilation and incorporate veranda spaces or large roof overhangs to protect the top of the wall and to protect windows from intense precipitation ${ }^{15}$. This contrasts with Northern European structures, where thick walls and associated building details were designed to isolate the occupants from the climate ${ }^{16}$. Globally we still use many of these traditional structures and in some countries they have a conserved status with protection and restrictions on how they may be adapted.

The increase in availability of transportation between major cities, and more generally in the developed world, mean that the availability of different materials has increased and so the potential for innovation in construction approaches has increased. One consequence of this innovation has been a move away from vernacular approaches and in some ways a standardizing of the aspiration for modern construction methods and styles. Another consequence is that there are now far wider combinations of materials present in regional construction practice than has ever been the case.

The proliferation of materials now used in construction means that the possible ways in which weathering and other degradation can occur is also increasing. We have a reasonable understanding of the performance of individual materials in different climates and so the design of building detailing can be used to help to protect the overall performance for a given climate. Manufacturers typically provide performance data which can help designers make pragmatic decisions about the suitability and potential service life when components are utilized in different climates. This may mean that certain combinations of construction need additional protection, or it may mean that alternative approaches need to be taken. An example of this from the UK is with guidance on where wall constructions could utilize an insulated cavity wall structure, and where precipitation exposure requires additional protection be implemented ${ }^{17}$. Further to this, local risk of materials durability problems is dependent upon a variety of attributes:

- Material specification, manufacture, and application (the quality of materials, ensuring that they are fit for purpose and that they have been correctly specified are key factors for performance);

- Design and building protection (architectural detailing to protect the vulnerable building elements (often at joints and openings), and design of infrastructure to protect the building against extreme events, such as drainage and defences for flood risk management);

- Building specific location (topography, urban/rural shelter, altitude, proximity to coast);

- Climate (the external climate loads discussed above).

The variety of materials present in modern construction makes a generalization of their degradation and weathering mechanisms challenging to convey within the space constraints of this review. For practitioners and building professionals who are faced with questions about weathering performance of specific materials, more detailed guidance should be sought from standards documentation or, in their absence, from the manufacturers. In order to convey an overview of typical weathering issues Table 1 presents a generic treatment of durability issues and their climate 
sensitivities for different material types. The contents of Table 1 are intended to be illustrative and not exhaustive. For a full description of the current state of the art, readers are encouraged to consider the surrounding literature. One difficult area, not covered in Table 1, is the growing use of composite materials where new material combinations are continually being developed. Whilst some composite materials have been evaluated and performance information published, for example with fibre reinforced polymers ${ }^{32}$, other composite materials have been less well studied.

One key point to note from Table 1 is that precipitation is a significant issue for many of the durability issues identified. Rainfall and the combination of wind and rain (driving rain) are important climatic parameters to evaluate for building performance. A number of countries, e.g. $\mathrm{UK}^{33}, \mathrm{Canada}^{34}, \mathrm{China}^{35}$ and India ${ }^{36}$ amongst others, have driving rain maps calculated; many other countries do not have this type of information. Such maps, based on historical weather patterns, enable practitioners to look at national variation into material performance and degradation risk. For example, the UK standard code of practice for slating and tiling for pitched roofs ${ }^{37}$ uses this type of exposure map. Understanding how buildings interact with the climate requires the application of detailed modeling and numerical simulation. This is a field which is itself beginning to explore and consider how climate change data can be incorporated into simulation work ${ }^{38}$.

\section{Potential impacts of climate change on the durability of materials under different climatic regimes}

Although climate change may lead to an increased risk of some deterioration mechanisms occurring ${ }^{39,40}$, it is highly unlikely that future climate will take material performance significantly outside of global experiences with materials. This should mean that for established materials there is negligible risk of new climate sensitive deterioration mechanisms developing. However, there is a significant likelihood that the rate and severity of some of the existing climate sensitive durability issues, as identified in Table 1, may change from current experience at a local level. This may be an increased rate and extent of degradation for materials, or for some mechanisms such as frost damage it could be a beneficial improvement with a reduction of problems for vulnerable materials in some locations. It may also be the case that risk assessments of climate change impacts on different building materials need to focus on different aspects of a particular climatic parameter. For example, in the case of rendered walls, duration of rain events might be of greater importance than the maximum intensity of precipitation while board clad walls might be more affected by the intensity of driving rain ${ }^{41}$. Similarly, for polymer materials in direct sunlight, the sum of ultraviolet radiation may determine the lifetime of the products, rather than the yearly averages in temperature.

As a pragmatic step towards identifying future risk issues, interested parties should consider the existing local problems that currently occur for materials and building fabric durability, and then determine whether the projected changes to climate for that location are likely to enhance or improve these. The complexity of issues that relate to durability and risk means that generalizing is impossible, even on a regional basis, and that for an accurate assessment of future risks building specific circumstances should be taken into consideration when determining adaptation plans and requirements ${ }^{42}$. 
Ideally, building specific assessments can be made and used to inform a whole life assessment of defect risk for a range of materials and associated components. This requires bringing together the detailed understanding of individual materials performance with detailed projections of future climate. However, one of the limitations with this has been that many of the durability issues can be caused by the interaction between a number of climate variables, for example temperature and precipitation together, but confidence in climate projections at this level of detail is low. The availability of weather generators ${ }^{43}$ has begun to allow data to be generated which makes viable the exploration of these composite variable effects. Weather generators can potentially produce synthetic weather data for precipitation ${ }^{44}$ and for other climate variables ${ }^{45}$ which are consistent with projections of future climates. The science behind weather generators is complex and developing, but caution is needed to ensure that they can plausibly produce the statistical relationships between climate variables. Many weather generators are conditioned on the statistical interrelationships of the current climate and under a changing climate these relationships may no longer be valid. Notwithstanding these uncertainties, if analysis of future climate related risk can be assessed, then this enables the utilization of some other more established tools ${ }^{46}$ for exploring the cost and benefits of adaptation options.

Although individual materials are unlikely to start manifesting new types of problem, there may still be some step changes in behavior for individual buildings with some structures that have been virtually problem free starting to manifest deterioration where the climate load may change significantly. In common with flood risk, materials durability is likely to be strongly affected by future changes in precipitation, and in particular the types of future precipitation pattern that we will experience. Concern about possible changes in precipitation patterns has spawned a wide range of impact studies, and in particular, extreme precipitation events are receiving a lot of research attention ${ }^{47}$, the consequences of which could be significant for a whole range of sectors of human activity. Many of the defects associated with buildings are related to the presence or movement of moisture in the building fabric ${ }^{48}$ - future changes to precipitation are likely to be an important indicator of change of risk to the building generally.

In areas where future exposure may be subject to significant change, the styles associated with vernacular practice may no longer be suitable. If this proves to be the case then the performance of existing and, in particular, historic buildings may be difficult to adapt in affected areas.

\section{Adaptation challenges for the preservation of existing and historic buildings}

As discussed in the introduction, many of the buildings we currently use will continue to be functional for decades and so be subjected to a changing climate. The challenge will be to maintain these buildings and, where necessary, adapt them to reduce problems and ensure ongoing utility and function. Adaptation is necessary where maintenance becomes ineffective or burdensome as the climate changes. It implies an intervention to consolidate or enhance the protection of a building ${ }^{49}$. Buildings may range considerably in form, type and age. The durability for the building fabric, or envelope as a whole, is dependent on the durability of the component materials ${ }^{50}$. The durability of individual component materials is strongly influenced by the architectural detailing and the protection that the structure may offer vulnerable components to excessive exposure to the climate (e.g. openness to driving rain). 
The climate sensitivity of different weathering mechanisms for materials shown in Table 1 indicate that materials durability will be impacted by climate change. The management of weathering of building materials has been addressed through appropriate remedial action in the form of building maintenance. In many cases, the immediate consequence of climate change for building materials will be a requirement for more frequent, and possibly more extensive, maintenance work. Where this may be neglected by building owners, it is likely to lead to an increased risk of building defects occurring $^{51}$. The identification and avoidance of defects in a changing climate may pose a significant challenge ${ }^{52}$. Traditional vernacular building approaches have evolved to minimize the rate of defects. However, with a changing climate such approaches will not respond sufficiently quickly. A more professional approach to identifying potential defects based on experience, or based on a scientific approach using measurement / testing, may offer better insight. However, experience of innovation cautions that in isolation none of these approaches will address the full spectrum of potential defects. A holistic, systematic response drawing from all three approaches (traditional vernacular, professional, and scientific) has been advocated to minimize defect occurrence ${ }^{52}$.

The following subsections explore the general issues associated with existing buildings, and some of the more sensitive issues that are particularly relevant to historic buildings.

\section{Existing buildings}

For existing buildings, changes to climate will cause a change in rate of development of existing weathering mechanisms. If no intervention is made to address this, there is a risk of increased deterioration leading to more serious building defects developing ${ }^{51}$ which will have direct consequences for the internal environment and for building occupants. As discussed above, the immediate consequence of increased rates of building component weathering will be an increased need and requirement for maintenance. For marginal changes to rates of degradation maintenance regimes may be adjusted to account for the change. However, if a more significant change to the rate of degradation occurs more significant adaptation may be needed. There are possible adaptations that could be considered as a way of mitigating some of the enhanced weathering rates which may lead to an unacceptable maintenance burden. Generically, these adaptations include improving the external weathering characteristics by use of appropriate coatings, overcladding, renders or other surface treatments. The effectiveness and availability of suitable products may vary between different material types.

Different climates will weather materials at different rates. The variability of climate and of climate change means that globally durability problems with materials will be enhanced by different amounts. There is a need for work to examine the implications of changing rates of weathering of materials, and from this identify potentially vulnerable structures. A pragmatic approach would be to explore which particular sections of the local building stock may suffer with enhanced degradation problems in light of projections of local climate change ${ }^{5}$. By identifying the most vulnerable buildings, planned and targeted adaptation can be realized. 


\section{Historic buildings}

In some countries historic buildings are afforded special protection status in order to protect and conserve their character. This protection itself provides additional challenges to finding adaptation solutions to climate change which do not detract from the historic nature of the building. Some of these historic buildings may already have a level of chronic performance problems, which may be made progressively worse as climate change develops ${ }^{53}$. The tension between the need to conserve these buildings and the need to make pragmatic decisions about adaptation will need to be addressed at the level of conservation jurisdiction, which may be national or regional.

Weathering and dampness can be chronic issues associated with historic buildings and the resulting challenges of conserving the structures can be significant ${ }^{54}$. In such historic buildings the internal finishes and contents can be equally important and challenging to protect ${ }^{55}$. The selection of appropriate materials to implement remedial or protective adaptation is a complicated issue with many potential consequences to evaluate, so a holistic approach is recommended. Detailed and wide ranging research is needed to explore potential problems and help to disseminate solutionssuch as that undertaken in the UK by the Engineering Historic Futures Project ${ }^{9}$. There can be numerous tensions in identifying an effective maintenance strategy for historic buildings and Green Maintenance has been devised as a concept to facilitate effective decision making in order to identify an optimum long term outcome for historic buildings ${ }^{56}$. Tools are being developed to help inform appropriate intervention choices with heritage buildings including for the UK that of the Sustainable Traditional Building Association ${ }^{57}$. Tools are being developed to deal with localized regional issues, however, overarching research is taking place at an international level to develop knowledge and understanding of problems for historic buildings. An excellent, recently completed, example of this is the European Commission funded project -Climate for Culture ${ }^{58}$. This study produced a wealth of resources including: case studies; impact studies; and decision making tools.

\section{Adaptation challenges for the planning of new buildings}

Considerable attention has been paid to trying to produce low carbon buildings through good building design in order to achieve mitigation targets for the future. Good low energy design based on consideration of whole life performance (including considering climate change) is being advocated by the Royal Institute of British Architects (RIBA) $)^{59}$. The challenge in adapting design practice for new buildings is to produce buildings that will be able to perform adequately for their full life as the climate changes and require an acceptable level of building maintenance over this time. There is a need for supporting standards and building codes that are not only appropriate for current climate need, but also account for future climate change. In many countries these codes and standards are still based on historic climate behaviour ${ }^{6}$. These standards will need to account for both the absolute changes in climate parameters as well as their intensity. In some countries, future climate is beginning to be looked at seriously in certain requirements for the development process of building codes and regulations, and this will filter into requirements made of new building development. However, this will only benefit those countries currently engaged with such development. To be effective, building codes need to give greater attention to climate-appropriate architectural details, for example the location and entry design of external services (electricity, water, and waste water) into a building that may be prone to increased future flood risk. The 
architectural and building design professions have a key role in ensuring future buildings are sufficiently robust to cope with changing climates. This requires attention to a range of issues including:

- Infrastructure requirements to service and protect the building ${ }^{60}$;

- Architectural detailing to enhance protection of vulnerable materials ${ }^{61,62}$;

- Materials selection and resilience ${ }^{39,40}$;

- Design and servicing to maintain an acceptable internal environment ${ }^{63,64}$.

A potential driver in influencing future building developments is the insurance industry ${ }^{65}$. In recent years, the insurance industry has paid out considerable claims associated particularly with flood and storm damage and they have taken a keen interest in evaluating how climate change may impact future risk, and how that risk may be managed. The affordability of future insurance cover is a serious issue ${ }^{66}$. The cost for reinstating damaged buildings varies with the types of materials used in the original construction. If the insurance industry can achieve a lower cost for reinstatement by favouring particular design choices, this may benefit the building owners in terms of premiums they need to pay.

Without appropriate building codes and standards that take into account future climate change an exact design solution may be difficult to formulate. Consideration of the traditional architectural detailing for regional climates that are equivalent to any location's future climate, particularly in terms of precipitation, may be a pragmatic starting point. However, this is more strongly an architectural design opportunity than a building materials challenge.

Lessons from Vernacular Construction
Traditional building design styles using local materials evolved around the world to produce
buildings which were suitable for their local historic climate. These vernacular construction styles
are still widely used, and the lessons about appropriate architectural detailing for coping with the
climate are worth reflecting on. The challenge for vernacular construction is that with a changing
climate these buildings may not offer the same robust protection to future climate in their current
regional locations. They do, however, offer a source of ideas about architectural detailing to other
regions whose climate is moving towards the historic climate in which the vernacular buildings were
built. This is a spatial analogue approach to exploring adaptation responses
spreading these lessons is in facilitating an effective regional knowledge transfer on good practice in
building design between potentially geographically separated regions. 


\section{Conclusion}

Climate has always had a direct impact on the degradation and subsequent durability of building materials. This has implications for the longer term maintenance required to sustain buildings and, where this maintenance proves difficult, the development of defects may occur within the buildings. Climate change will have an effect on the degradation rate of building materials, and at worst will lead to an acceleration of the decay of the materials, which will increase the level of maintenance needed to sustain buildings without defects. Many of the degradation mechanisms are in part driven by precipitation, so any changes to the amount, nature and seasonality of precipitation will impact on the rate of degradation. Globally, it is unlikely that new durability problems will occur with established materials. At a local level novel climates ${ }^{68}$ for a region may evolve and as a result problems will occur which haven't been experienced in that region before. For buildings that have pre-existing climate-related problems, climate change may exacerbate these and this is likely to be a particular challenge for historic buildings that have special conservation requirements.

An approach to adaptation is to first identify the likely future risks, and some countries have actively begun this process. Existing risks can be explored for materials durability and potential future risks can be evaluated by looking at the performance of key materials in current climates that are analogous to the projections of future climate. Timely application of this will allow the most vulnerable part of the building stock to be identified and, where appropriate, will allow adaptation programmes to be formulated to make most efficient use of resources. Maintenance is likely to be a key mechanism for much of the existing building stock to avoid significant defects occurring as the climate changes. For future new buildings, design standards and building codes need to be developed to focus attention on future climate rather than just current climate. Computer modeling may be a useful tool to help with decision making, however, validation of models used is important and the reliability of models for predictions of performance over decades has not been possible, so any adaptation solutions need to be carefully trialed and monitored.

Traditional vernacular building styles may offer an opportunity for learning design lessons and adapting design practice which may help facilitate appropriate climate protection. The difficulty with looking at vernacular styles is that at a local level the climate is adapting away from the traditional climate, so the local vernacular style may not be appropriate and consideration may need to be given to practice from other regions or countries.

\section{References}

1. European Commission. Commission Directive EPBD recast, Directive 2010/31/EU 19 May 2010, on energy performance in buildings (recast), Official Journal of the European Union, 2010.

2. Capon R, Oakley G. Climate Change Risk Assessment for the Built Environment Sector. DEFRA, 2012. 
3. Sharma A, Saxena A, Sethi M, Shree V. Life cycle assessment of buildings: a review. Renewable and Sustainable Energy Reviews, 2011, 15(1), 871-875.

4. Meikle JL, Connaughton JN. How long should housing last? Some implications of the age and probable life of housing in England. Construction Management and Economics, 1994, Vol. 12, Iss. 4, 1994

5. Almås A-J, Lis $\varnothing \mathrm{KR}$, Hygen HO, Øyen CF, Thue JV. An approach to impact assessments of buildings in a changing climate. Building Research \& Information, 2011, 39(3), 227-38.

6. El-Dash K. Service Life Prediction for Buildings Exposed to Severe Weather. Journal of Asian Architecture and Building Engineering, 2011, 10(1), 211-215.

7. Flourentzou F, Brandt E, Wetzel C. MEDIC - a method for predicting residual service life and refurbishment investment budgets. Energy and Buildings, 2000, 31(2), 167-170.

8. UNFCCC. Technologies for adaptation to climate change. UNFCCC, 2006.

9. Cassar M, Hawkings $C$ (eds.) Engineering historic futures: stakeholders dissemination and scientific research report. 2007. Centre for Sustainable Heritage, UCL, London, UK

10. Milly PCD, Wetherald R, Dunne KA, Delworth TL. Increasing risk of great floods in a changing climate. Nature, 2002, 415(6871), 514-517.

11. Wilson E, Piper J. Spatial planning and climate change. London: Routledge, 2010.

12. Steen B. Built by hand: vernacular buildings around the world. Gibbs Smith, 2003.

13. Addleson L, Rice C. Performance of Materials in Buildings: A study of the Principles of the Agencies of Change. Butterworth-Heinmann, Oxford, 1991.

14. Hyde R. Climate responsive design: a study of buildings in moderate and hot humid climates. Taylor \& Francis, 2013.

15. Wong NH, Chen Y. Tropical urban heat islands: climate, buildings and greenery. Routledge., 2008.

16. Van Hoof J, Van Dijken F. The historical turf farms of Iceland: Architecture, building technology and the indoor environment. Building and Environment, 2008, 43(6), 1023-1030.

17. BRE. Thermal Insulation: Avoiding the Risks. BRE Report BR 262. London: BRE, 2002.

18. Lourenço PB, van Hees R, Fernandes F, Lubelli $B$. Characterization and damage of brick masonry. In Costa A, Guedes JM, Varum H. ed. Structural rehabilitation of old buildings. Springer Berlin Heidelberg. 2014 109-130.

19. Brimblecombe P, Bonazza A, Brooks N, Grossi CM, Harris I, Sabbioni C. Impact of Climate Change on Earthen Buildings. InTerra 2008: The 10th International Conference on the Study and Conservation of Earthen Architectural Heritage. Getty Publications. 2011: 278.

20. Abu Bakar B H, Ibrahim W, Haziman M, Johari M. A review: durability of fired clay brick masonry wall due to salt attack. International Journal of Integrated Engineering 1.22011 : 111-127.

21. Prikryl, R. and Viles, H.A. (eds.) Understanding and managing stone decay. The Karolinum Press; Prague, 2002.

22. Butlin, RN. Effects of air pollutants on buildings and materials. Proceedings of the Royal Society of Edinburgh. Section B. Biological Sciences, 97, 1990: 255-272.

23. Goudie AS, Viles HA. Salt Weathering Hazards. Wiley, 1997, 256.

24. Nofal M, Kumaran K. Biological damage function models for durability assessments of wood and wood-based products in building envelopes. European Journal of Wood and Wood Products, 2011, 69(4), 619-631. 
25. Haque N. Delamination in Timber Induced by Drying. In Delamination in Wood, Wood Products and Wood-Based Composites. Springer Netherland, 2011, 197-212.

26. Uhlig HH. Uhlig's corrosion handbook (Vol. 51). R. W. Revie (Ed.). John Wiley \& Sons, 2011.

27. Chaochanchaikul K, Rosarpitak V, Sombatsompop N. Photodegradation profiles of PVC compound and wood/PVC composites under UV weathering. Express Polymer Letters, 2013, $7(2), 146-160$.

28. Seldén R. The effect of heat ageing on fracture toughness in uPVC pressure pipe. Polymer testing, 1987, 7(6), 431-444.

29. Cabrera J G. Deterioration of concrete due to reinforcement steel corrosion. Cement and concrete composites, 1996, 18(1), 47-59.

30. Skalny J, Brown PW. Sulfate attack on concrete. Taylor \& Francis. 2002.

31. Garvin S L, Wilson J. Environmental conditions in window frames with double-glazing units. Construction and Building Materials,1998, 12(5), 289-302.

32. Liao K, Schultheisz CR, Hunston D L, Brinson LC. Long-term durability of fiber-reinforced polymer-matrix composite materials for infrastructure applications: a review. Journal of advanced materials, 1998, 30(4), 3-40.

33. Lacy RE. Driving-Rain Index. BRE Report, Building Research Establishment, 1976.

34. Boyd DW. Driving-rain map of Canada. Technical Note no. 398, Division of Building Research, National Research Council of Canada, Ottawa, 1963.

35. Sauer P. An annual driving rain index for China. Building and Environment, 1987, 22, 239240.

36. Chand I, Bhargava PK, 2002. Estimation of driving rain index for India. Building and Environment, 2002, 37 (5), 549-554.

37. British Standards, BS 5534: 2014. Slating and tiling for pitched roofs and vertical claddingcode of practice. British Standards Institution, London, 2014.

38. Blocken BJE, Briggen PM, Schellen HL, Hensen JLM. Climate change and high-resolution whole-building numerical modelling., in Effect of Climate Change on Built Heritage, 11-12 March 2010, Eindhoven, WTA-34 edn. Bunnik T., de Clercq H, van Hees R, Schellen H, Schueremans L. (eds) 2010. Wissenschaftlich-Technische Arbeitsgemeinschaft fur Bauwerkserhaltung und Denkmalpflege (WTA) Publications, Pfaffenhofen, Germany, 230pp.

39. Graves HM, Phillipson MC. Potential implications of climate change in the built environment. Construction Research Communications, 2000.

40. Nijland TG, Adan OC, van Hees RP, van Etten B D. Evaluation of the effects of expected climate change on the durability of building materials with suggestions for adaptation. Heron, 2009, 54(1), 37-48.

41. Nordvik V, Lisø KR. A primer on the building economics of climate change. Construction Management and Economics, 2004, 22, 765-775.

42. Adger NW, Arnell NW, Tompkins E L. Successful adaptation to climate change across scales. Global environmental change, 2005,15(2), 77-86.

43. Kilsby CG, Jones PD, Burton A, Ford AC, Fowler HJ, Harpham C, James P, Smith A, Wilby RL. A daily weather generator for use in climate change studies. Environmental Modelling \& Software, 22, no. 12, 2007: 1705-1719.

44. Wilks DS. Use of stochastic weather generators for precipitation downscaling. WIRES Clim Change 2010, 1:898-907. 
45. Wilks DS. Stochastic weather generators for climate-change downscaling, part II: multivariable and spatially coherent multisite downscaling. WIREs Clim Change 2012, 3:267278.

46. Willows R, Reynard N, Meadowcroft I, Connell R. Climate adaptation: Risk, uncertainty and decision-making. UKCIP Technical Report. UK Climate Impacts Programme, 2003.

47. Palmer TN, Räisänen J. Quantifying the risk of extreme seasonal precipitation events in a changing climate. Nature, 2002, 415(6871), 512-514.

48. Richardson B. Defects and Deterioration in Buildings: A Practical Guide to the Science and Technology of Material Failure. Routledge, 2002.

49. Douglas J, Ransom B. Understanding building failure. $4^{\text {th }}$ edition, Routledge, 2013.

50. Peris Mora E. Life cycle, sustainability and the transcendent quality of building materials. Building and Environment, 2007, 42(3), 1329-1334.

51. Ahzahar N, Karim NA, Hassan SH, Eman J. A study of contribution factors to building failures and defects in construction industry. Procedia Engineering, 2011, 20, 249-255.

52. Forster AM, Fernie S, Carter K, Walker P, Thomson D. Innovation in low carbon construction technologies: An historic analysis for obviating defects. Structural Survey, 2015, 33(1), 5272.

53. Cassar M, Pender R. Climate change and the historic environment. Centre for Sustainable Heritage, University College London, 2005.

54. Wood, C. (2004). Rain Damage to Masonry: Wall Cappings and Towers. English Heritage Conservation Bulletin, 45, 38.

55. Lankester $\mathrm{P}$, Brimblecombe $\mathrm{P}$. The impact of future climate on historic interiors. Science of the Total Environment, 2012, 417, 248-254.

56. Forster AM, Carter K, Banfill PFG, Kayan B. Green maintenance for historic masonry buildings: an emerging concept. Building Research \& Information, 2011, 39(6), 654-664.

57. English Heritage. Responsible Retrofit. Conservation Bulletin, 2014, 72, 9-11.

58. Climate for Culture (2014) Climate for Culture Project [Online] available from http://www.climateforculture.eu/ (accessed 20 October 2015)

59. RIBA. Low carbon toolkit: 08 whole life assessment for low carbon design. Royal Institue of British Architects, London, 2007.

60. Hamin EM, Gurran N. Urban form and climate change: Balancing adaptation and mitigation in the US and Australia. Habitat international, 2009, 33(3), 238-245.

61. Brunskill RW. Illustrated handbook of vernacular architecture. 1978. Faber \& Faber, London.

62. Emmitt S, Olie J, Schmid P. Principles of architectural detailing. 2009. John Wiley \& Sons.

63. Krishan A. (ed.).Climate responsive architecture: a design handbook for energy efficient buildings. 2001. Tata McGraw-Hill Education.

64. Holmes MJ, Hacker JN. Climate change, thermal comfort and energy: Meeting the design challenges of the 21st century. Energy and Buildings, 2007, 39(7), 802-814.

65. Mills E. Insurance in a climate of change. Science, 2005, 309(5737), 1040-1044.

66. Mills E, Lecomte E. Availability and affordability of insurance under climate change: $A$ growing challenge for the US. USA: Ceres, 2005.

67. Parry ML, Canziani OF, Palutikof JP and Co-authors. Technical Summary. Climate Change 2007: Impacts, Adaptation and Vulnerability. Contribution of Working Group II to the Fourth Assessment Report of the Intergovernmental Panel on Climate Change, Parry ML, Canziani OF, Palutikof JP, van der Linden PJ, Hanson CE, (eds.). 2007, Cambridge University Press, Cambridge, UK, 23-78. 
68. Williams JW, Jackson ST, Kutzbach JE. Projected distributions of novel and disappearing climates by 2100AD. Proc. Natl. Acad. Sci., 2007, 104, 5738-5742.

Tables

Table 1. Climate Sensitivity of the Durability of Generic Material Types

\begin{tabular}{llll}
\hline Material Type & Durability Issues & Climate Dependence & References \\
\hline Brick and & - Frost damage & Freeze-thaw cycles & 18 \\
Ceramics & - Shrinkage of unfired materials & Precipitation and drying & 19 \\
& - Salt staining & Precipitation and drying & 20 \\
\hline \multirow{2}{*}{ Stone } & - Weathering \& erosion & Temperature, precipitation & 21 \\
& - Acid deposition & Precipitation (with pollution) & 22 \\
& - Salt attack & Precipitation and drying & 23 \\
\hline Wood & - Biological deterioration & Temperature and precipitation & 24 \\
& - Warping \& structural movement & Uneven drying & 25 \\
\hline Metals & - Various corrosion mechanisms & Temperature, precipitation & 26 \\
\hline Plastics / & - UV deterioration & UV exposure, temperature & 27 \\
Polymers & - Thermal ageing & Temperature & 28 \\
\hline Concrete & - Corrosion of reinforcement & CO, temperature, drying & 29 \\
& - Chemical and salt attack & Precipitation, Temperature & 30 \\
& & and drying & \\
\hline Glazing & Failure of double glazing seals & Precipitation and humidity & 31 \\
\hline
\end{tabular}

Related Articles

\begin{tabular}{|l|l|}
\hline \multicolumn{1}{|c|}{ DOI } & \multicolumn{1}{c|}{ Article title } \\
\hline wcc.26 & Assessing Impacts of Climate Change \\
\hline wcc.85 & Use of stochastic weather generators for precipitation downscaling \\
\hline wcc.116 & Evaluating regional vulnerability to climate change: purposes and methods \\
\hline
\end{tabular}

